\title{
A Review on Botswana Coal Potential from a Pyrolysis and Gasification Perspective
}

\author{
Mmoloki Makoba1*, Daniel Erich Botha1,3, Mpho Thabang Rapoo, László Zsolt Szabó1,2, \\ Thapelo Shomana', Paul Șerban Agachi' ${ }^{1,2}$, Edison Muzenda'

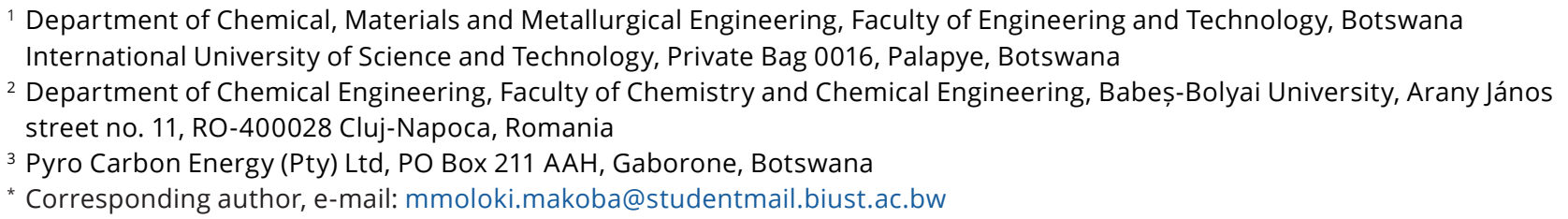

Received: 25 July 2018, Accepted: 12 December 2018, Published online: 06 July 2020

\begin{abstract}
Coal pyrolysis and gasification are promising options for the future of Botswana as the country has large coal reserves with severe limitations in terms of export options. Coal characterization facilities will be required in order to harness its full potential and methods such as proximate, ultimate and chemical structure analysis (FTIR, Raman spectroscopy and X-ray diffraction techniques) were investigated. The paper presents a brief history of pyrolysis and gasification, typical types of the reactors as well as factors that influence product selection for Botswana coal. Coal pyrolysis and gasification are complex processes and it is difficult to define the mechanisms of product formation. However, there are several kinetic models that are relevant to the sub-bituminous coal of Botswana which were proposed by researchers to describe the formation of the compounds and mathematical models that were validated by other researchers on mass and heat transfer as also presented herein.
\end{abstract}

Keywords

sub-bituminous coal, pyrolysis, gasification, characterization, kinetics

\section{Introduction}

Botswana has in excess of 212 billion metric tons of known coal deposits of which the vast majority is ranked as medium to low grade sub-bituminous coal. The majority of the coal deposits are contained in what is referred to as the Central Kalahari Karoo Basin. The country utilizes this resource mainly as a combustion fuel for electricity generation in the Morupule Power Station near Palapye. The coal is mined at the Morupule Coal Mine with a life that extends to at least year 2032, which is the current period of the lease [1]. And although the mine is currently busy with an expansion project, Botswana coal remains currently vastly underutilized.

Botswana, being land locked as seen in Fig. 1 [2], is far from any ports and means of exporting coal have been investigated extensively. Agreements with neighboring countries to build railroads already exist (Fig. 2).

However, developing multiple rails simultaneously is not economically viable and with interwoven interests of several shareholders and countries the situation is leading to huge delays in railway construction projects [3].

In order to improve the utilization of Botswana coal, it is necessary to find alternative economically feasible methods of extracting higher value products. Botswana

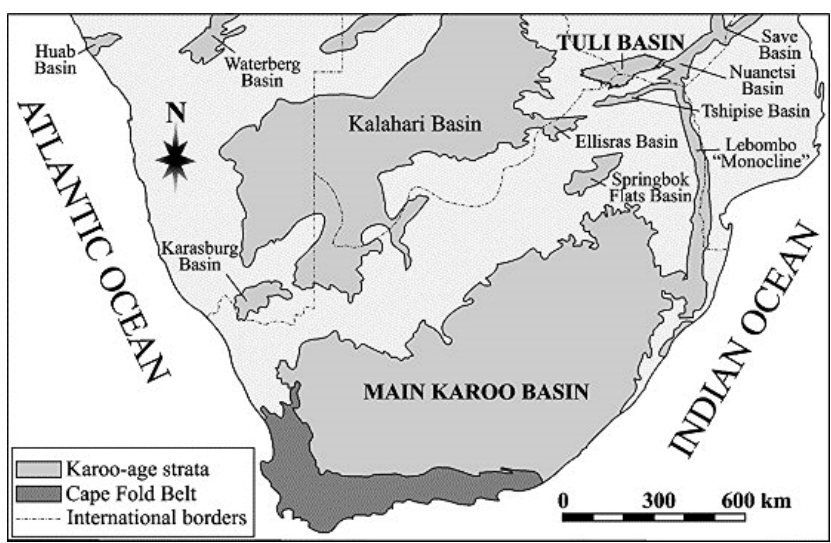

Fig. 1 The Karoo Supergroup in Southern Africa [2]. 


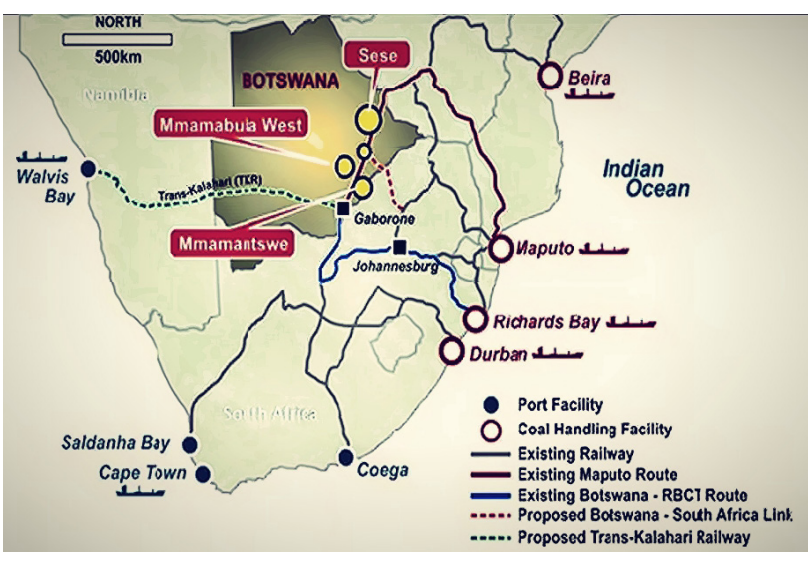

Fig. 2 Five options to export Botswana coal via Namibia, South Africa (2 ports) or Mozambique (2 ports) [3].

International University Science \& Technology (BIUST) in collaboration with industry partners has embarked on a number of research projects related to this national goal and this review paper summarizes some of the literature that has been studied as part of this research program.

Laying a foundation for the development of technology to convert the sub-bituminous coal of Botswana into high value products required a survey of literature produced on other similar ranks of coal elsewhere in the world and relating it to the specific properties of Botswana coal. To this effect, the subject was studied by considering the history and development of pyrolysis and gasification, coal characterization, product selection and manipulation, chemical kinetics and mathematical modelling of the processes involved.

The objective of this paper is therefore to review the current status of pyrolysis, gasification and other related subjects, what has been previously achieved, and what technology and methods are applicable and usable for the beneficiation of Botswana's coal.

\section{Coal pyrolysis and gasification history and methods}

Pyrolysis and gasification are thermochemical conversion processes where valuable products (char, pyrolysis oil and syngas) are extracted from carbonaceous materials (e.g. coal) by application of heat.

Coal structure is composed of the immobile phase structure (one to multiple aromatic rings and different types of functional groups) clustered together by mobile phases being aliphatic and ether bridges. The points that join the aromatic rings together are covalently bonded. There are small holes that exist within the chain called interstices where small aliphatic molecules may be trapped [4]. Minerals like quartz $\left(\mathrm{SiO}_{2}\right)$ may also be present. Depending on the formation of coal, individual coal structures vary widely.
Pyrolysis takes place in an oxygen-deprived atmosphere and during the first stage of pyrolysis, coal structure breaks down at the mobile aliphatic and ether bridges. It is possible to change the quality and quantity of the products by changing parameters like the temperature, heating rate, residence time and condensation rate.

The gasification process occurs at a higher temperature and pressure and also requires the addition of an agent such as steam or oxygen.

Thermochemical conversion processes have been applied to biomass for thousands of years to convert wood into charcoal at low temperatures and slow heating rates (torrefaction). The ancient Egyptians also used pyrolysis to produce methanol which they used for embalming and pyrolysis remained the main source of methanol until the $20^{\text {th }}$ century.

During the $20^{\text {th }}$ century much research has been done by various companies and continuous feed processes were developed for the first time. This led to many different pyrolysis reactor designs, each favoring their operating regime covering:

1. applied temperature (low: below $400{ }^{\circ} \mathrm{C}$, medium: up to $600^{\circ} \mathrm{C}$ and high: above $600^{\circ} \mathrm{C}$ ),

2. heating rate (slow, medium, fast and flash pyrolysis),

3. pressure (vacuum up to several atmospheres) and

4. a wide range of catalytic processes.

One of the main advantages of pyrolysis is the relatively low temperatures of $400{ }^{\circ} \mathrm{C}-700{ }^{\circ} \mathrm{C}$, which are lower than those required for gasification and combustion which are much higher [5]. This makes it possible to utilize waste energy from the system thereby eliminating the need for energy supply from other sources and could result in a cheaper alternative compared to other energy conversion processes [6].

However, if the goal is maximum syngas production, it is necessary to convert all the carbon which remains in the char and for this, the higher temperatures and pressures of typical gasification processes are required.

\subsection{Classification of pyrolytic systems}

Pyrolytic systems can be classified in various ways e.g. the way that heat is applied or the way the solids are handled. In order to develop feasible methods for the exploitation of local coal it is necessary to appreciate the different pyrolytic systems. In the process of developing technology that is optimized for local coal and local conditions it may be necessary to adapt and/or combine existing systems. 


\subsubsection{Classification by heat application method}

Partial combustion inside reactor

A limited amount of oxygen is allowed to enter the reactor which combusts a portion of the feed material to provide the process heat.

Direct heat transfer by external combustion of fuel

A portion of the pyrolysis vapors / gases or other fuel is combusted outside the reactor and the exhaust gases are then passed through the solid medium in the reactor.

Direct heat transfer using hot inert material

An inert material such as sand is heated up externally and then fed into the reactor to mix with raw material thereby transferring its heat by means of direct contact. This inert material is then separated from the char, heated and recycled back into the process.

Indirect heat transfer through the reactor wall

Heat is applied to the reactor wall, which then heats up the raw material within by means of conduction and radiation. Indirect heat transfer of recycled gases

A portion of the non-condensable pyrolysis gases (syngas) is combusted and the heat produced is used to heat up the recycled portion of the syngas, which then exchanges heat with the coal while passing through the reactor.

\subsubsection{Classification by solids handling method}

No solid movement (batch)

The reactor is filled up with coal while it is cold. After filling the reactor, it is sealed and then heated up until the reaction is complete. Heating is then removed and the reactor is allowed to cool down before opening it to remove the char. This process is repeated batch by batch.

Moving bed (shaft reactors)

A vertical reactor is loaded continuously or at regular intervals through lock hoppers to form a bed within the reactor. Char is discharged from the bottom of the reactor in a similar way. As the char is removed, the bed moves downward by means of gravity while a counter current sweeping gas is used to transport pyrolysis vapors out of the reactor.

Mechanically forced

Coal can be forced through the reactor in various ways, e.g. by means of a rotary kiln or auger.

Flow-induced

The two most widely used configurations in this category are the fluidized bed and Circulating Fluidized Bed (CFB) type. The coal has to be ground fine in the flow-induced category and the solid material is then entrained in a gaseous fluid while being heated up. In some cases, an inert solid heating medium such as sand can be used to form a fluidized bed.

\subsection{Gasification}

Coal gasification is the process in which coal is partially combusted. It involves the reaction of solid coal with air and steam to yield gaseous products that are able to be used as fuel gas, chemical feedstock and other products [7].

Fig. 3 illustrates the three processes that occur in a typical gasifier being:

1. drying and pyrolysis

2. combustion

3. gasification.

In drying and pyrolysis, water that is fed with coal and moisture within the coal is driven off by heat introduced. Then the weak bonds in coal start to break producing gases, tar and char. In the combustion process, the oxygen supplied to the reactor reacts with combustible substances in the system forming carbon dioxide and water. These two products then undergo reduction when they get in contact with char to produce carbon monoxide and hydrogen in the process of char gasification. The system goes through a series of endothermic and exothermic reactions which need to be balanced otherwise there will be a low carbon conversion in the gasifier.

Under practical conditions these coal gasification processes take place:

1. Syngas is produced from the first stage of coal gasification which is devolatilization and this is followed by char gasification together with some secondary processes.

2. Coal molecules break down at weak aliphatic and ether bonds in the process of pyrolysis during which Volatile Matter is released [all gases, tar (liquid hydrocarbons), and light gaseous hydrocarbons].

$$
\text { Coal } \rightarrow \text { char }(\mathrm{C})+\text { coal volatiles }(\mathrm{VM}) ;+\Delta H
$$

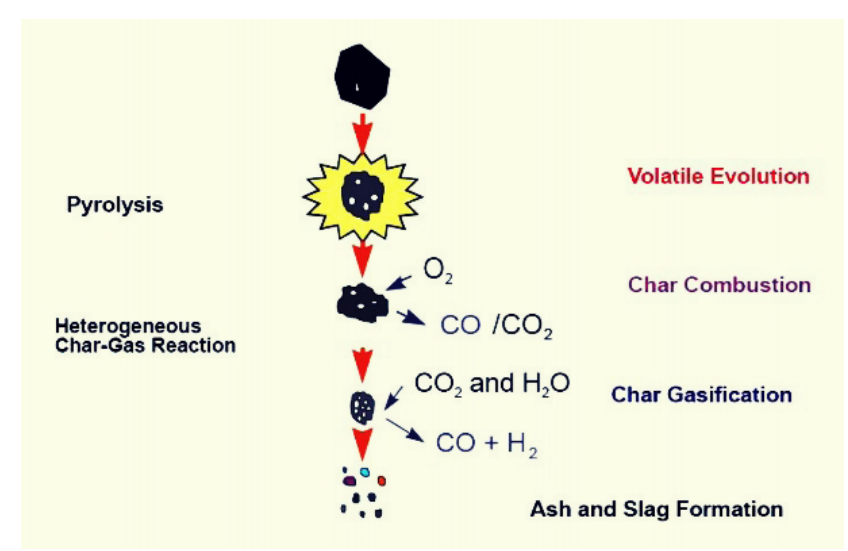

Fig. 3 Pictorial representation of gasification process [8] 
3. Pyrolysis is then followed by hydrocracking which is the addition of hydrogen to the tar molecules present in the Volatile Matter. This process produces methane.

$\mathrm{VM}+\mathrm{H}_{2} \rightarrow \mathrm{CH}_{4} ;-\Delta H$

4. Tar then undergoes a gasification process producing carbon monoxide and hydrogen.

$$
\mathrm{VM}+\mathrm{H}_{2} \mathrm{O} \rightarrow \mathrm{CO}+\mathrm{H}_{2} ;+\Delta H
$$

5. The char undergoes hydrogasification and gasification reactions as shown below in their respective manner. During hydrogasification, hydrogen is added to the hydrocarbon to produce alkanes, and in this case, light alkane methane (Eq. (4)). Char is then gasified to carbon monoxide and hydrogen by both steam and carbon dioxide to produce hydrogen and carbon monoxide respectively as per Eq. (5) and Eq. (6) respectively.

$$
\begin{aligned}
& \mathrm{C}+2 \mathrm{H}_{2} \rightarrow \mathrm{CH}_{4} ;-\Delta H \\
& \mathrm{C}+\mathrm{H}_{2} \mathrm{O} \rightarrow \mathrm{CO}+\mathrm{H}_{2} ;+\Delta H \\
& \mathrm{C}+\mathrm{CO}_{2} \rightarrow 2 \mathrm{CO} ;+\Delta H
\end{aligned}
$$

6. Other reactions that take place in a gasifier are water shift reactions and char combustion (Eqs. (7) and (8) respectively). In the water shift reaction process, carbon monoxide is passed through steam, oxygen atoms from water attaches to carbon monoxide forming carbon dioxide and hydrogen as in Eq. (7). This is a method to increase hydrogen yield.

$$
\begin{aligned}
& \mathrm{CO}+\mathrm{H}_{2} \mathrm{O} \rightarrow \mathrm{CO}_{2}+\mathrm{H}_{2}-\Delta H \\
& \mathrm{C}+\mathrm{O}_{2} \rightarrow \mathrm{CO}_{2}-\Delta H
\end{aligned}
$$

\subsection{Thermodynamics}

Char gasification reactions (Eq. (5) and Eq. (6)) are endothermic with energy of about $120-160 \mathrm{~kJ} / \mathrm{mol}$. These endothermic reactions are favored at temperatures above 1000 K. Reaction (Eq. (2)) shows to be slightly exothermic with enthalpy $\Delta H$ of -32 to $-88 \mathrm{~kJ} / \mathrm{mol}$. Unlike endothermic reactions, this reaction is favored below temperatures of $1000 \mathrm{~K}$. According to [7], the combustion reaction completes while gasification reactions and shift reactions approach pseudo equilibrium.

\section{Coal characterization}

Coal is generally thought to be heterogeneous and amorphous in nature. It is also widely known that coal has different types and ranks depending on the conditions and compositions at the first stages of coalification. Different coals will require different methods of processing and in order to develop technology suitable for Botswana coal, it is necessary to understand its nature. For coal to be understood it has to be taken through a series of tests, and analysis called characterization.

Coal characterization is the use of analytical techniques to identify specific physical and chemical properties of coal in understanding the nature in which this fuel was formed or altered with time. Characterization evaluates the use of coal by identifying different elements contained in it, as well as its structure and has become the industry standard for optimizing energy consumption from coal.

Tests performed on coal samples in order to determine their value and potential uses are the proximate analysis, the ultimate (physical and chemical) analysis as well as other advanced techniques.

Characterization tests should be carried out under strict laboratory conditions and the laboratories should be approved by the international standards (ASTM, ISO, AS, D) [9]. The characterization approach depends on the type of application. For pyrolysis and gasification applications the most important of these are described in the following subsections.

\subsection{Calorific Value}

Calorific Value (CV) indicates the amount of heat energy that can be liberated from burning a certain amount of coal. Calorific value of coal is traditionally determined using a bomb calorimeter. However, [10] believes a lot should be done in getting more accurate and rapid calorific values. This analysis has seen the introduction of $\gamma$-ray technique and laser-induced breakdown spectroscopy together with models that will correct any deviations from the spectrum [10]. Table 1 [11] lists typical calorific values for various coal sources in Botswana which were determined traditionally in a laboratory.

\subsection{Proximate analysis}

Proximate analysis determines the physical properties of coal. It measures the percentage by weight of moisture content, Volatile Matter (VM), Fixed Carbon (FC), Ash and Sulphur (S) content. Typical results for Botswana coals are presented in Table 1. 
Table 1 Typical proximate analysis properties of various Botswana coals $(\mathrm{wt} \%)$

\begin{tabular}{lccccc}
\hline Location & $\mathrm{CV}(\mathrm{MJ} / \mathrm{kg})$ & Ash \% & VM \% & $\mathrm{S} \%$ & $\mathrm{FC}$ \\
\hline Morupule & 24.4 & 21.1 & 24.3 & 1.44 & \\
Mmamabula & 23.95 & 20.8 & 25 & 2.19 & \\
Letlhakeng - E2b & 25.04 & 18.7 & 28.3 & 1.86 & \\
Letlhakeng - G1 & 22.83 & 23.3 & 25.3 & 1.41 & \\
Foley & 24.65 & 17.7 & 25 & 0.7 & 57.3 \\
Dukwe & 24.8 & 22.1 & 25.4 & & \\
\hline
\end{tabular}

Sub-bituminous coals normally contain moisture in the range $10-45 \mathrm{wt} \%$, Fixed Carbon: $35-45 \mathrm{wt} \%$, Volatile Matter: 20-35 wt $\%$, Ash less than $10 \mathrm{wt} \%$ and Sulphur less than $2 \mathrm{wt} \%$ [12]. Moisture content helps in binding fines in coal ore; however, it reduces heat content per $\mathrm{kg}$ of coal. Volatile Matter determines the flammability of coal and consists of incombustible gases (carbon dioxide and nitrogen), tar (i.e. liquid hydrocarbons) and light gaseous hydrocarbons. Fixed Carbon is the solid that remains after Volatile Matter is driven off. It consists of mainly carbon and therefore plays an important part in the heating value of coal. Ash results from impurities that could not burn during the process. These impurities have side effects in that they reduce efficiency of the process [12].

\subsection{Ultimate analysis}

Ultimate analysis determines elements contained in coal, and the solid and gaseous compositions. Such elements include but not limited to carbon, hydrogen, nitrogen, oxygen, sulphur. It is important to know the chemical composition of coal which will later determine its combustibility, which can only be determined through ultimate analysis by a skilled chemist in a well-equipped laboratory. The ultimate analysis is used to determine the amount of air required for combustion, the volume and composition of the combustion gases [13]. This information can be used to find flame temperature and flue duct design.

The ultimate analysis values (i.e. $\% \mathrm{C}, \% \mathrm{H}$ and $\% \mathrm{~N}$ ) can be calculated from the proximate analysis results as follows [14]:

$$
\begin{aligned}
& \% \mathrm{C}=0.97 \mathrm{C}+0.7(\mathrm{VM}-0.1 \mathrm{~A})-\mathrm{M}(0.6-0.01 \mathrm{M}) \\
& \% \mathrm{H}=0.036 \mathrm{C}+0.086(\mathrm{VM}-0.1 \mathrm{~A})-0.0035 \mathrm{M}^{2}(1-0.02 \mathrm{M})
\end{aligned}
$$

$$
\% \mathrm{~N}=2.10-0.020 \mathrm{VM}
$$

where: $\mathrm{C}$ is \% Fixed Carbon, $\mathrm{A}$ is $\% \mathrm{Ash}, \mathrm{VM}$ is the $\%$ Volatile Matter, and $\mathrm{M}$ is the \% Moisture.

\subsection{Petrographic analysis}

Coal is a result of a sequence of biological and geological processes. Petrography is a powerful tool in monitoring coal blending. It is a microscopic method for characterizing coal into organic (maceral) and inorganic (mineral) constituents. Maceral composition in coal is responsible for coal reactivity and conversion. There are three principal categories of maceral composition; vitrinite, inertinite and exinite [15].

\subsection{Ash Fusion Temperature}

Ash Fusion Temperature (AFT) is important in understanding fouling and slagging in coal conversion processes [16]. It gives the melting temperatures of coal ash to slag. Slagging could cause problems in reaction chambers and piping in the reactor. Jak [17] used Fact Sage thermodynamic computer package to develop a new AFT model. Liu et al. [16] gathered there are several more methods to predict this behavior even though they are limited to a range of conditions; the partial least-squares regression, a back propagation neural network model, and relationship between AFTs and coal ash composition.

\subsection{Characterization of coal char structure by analytical techniques}

To get more information about coal other than by the conventional analysis, advanced analysis has to be carried out.

\subsubsection{X-ray diffraction technique}

$\mathrm{X}$-ray diffraction is used to determine the atomic and molecular structure of a crystal which tells the quality and content of the coal mineral. This analysis does not only help in the mineralogical compositions but also the structural parameters of carbon. It confirms the presence of mineral constituents.

\subsubsection{Fourier Transform Infrared Spectroscopy (FTIR)}

The FTIR is an analytical technique used to determine the different functional groups present in a coal structure. It is able to reveal aromatic and aliphatic structures (carbo-hydrogenated structures), heteroatomic functions (oxygenated structures) and minerals present in coal. FT-IR study shows the presence of aliphatic $-\mathrm{CH},-\mathrm{CH}_{2}$ and $-\mathrm{CH}_{3}$ groups, aliphatic $\mathrm{C}-\mathrm{O}-\mathrm{C}$ stretching associated with $-\mathrm{OH}$ and -NH stretching vibrations and HCC rocking [18].

\subsubsection{Raman spectroscopy}

Raman spectroscopy is used to examine the chemical structures of carbon and minerals associated in the coal structure. It can also be used to study changes in carbon 
structure during gasification. The Raman character of the natural organic matter in coal has been studied and related to the Raman bands of the structural order of the amorphous carbons [19].

\section{Product selection and manipulation}

Coal can be converted into a number of useful products, the products obtained depend on the type of conversion process that the coal goes through. This paper will look at the products obtained from gasification and pyrolysis. Fig. 4 depicts the different coal conversion methods.

\subsection{Pyrolysis products}

The main products from pyrolysis include vapors, tar, mixture of gases and char [20]. These pyrolysis vapors can be condensed into light and heavy oils. They can also be converted into syngas via steam reforming, and further processing for synthetic liquid fuels. More applications of the vapors include conversion to non-energy products [6]. This is an indication of the versatility of the products of coal pyrolysis.

$$
\text { Coal } \rightarrow \operatorname{Gas}\left(\mathrm{CH}_{4}, \mathrm{CO}, \mathrm{H}_{2}, \text { etc. }\right)+\operatorname{Liquid}(\operatorname{tar})+\operatorname{Solid}(\text { coke })
$$

The yields and nature of the products are influenced by a number of factors including; coal type/characterization, coal particle size, carrier gas, pressure, temperature, residence time and heating rate [21]. These parameters also determine the reaction pathway that occurs during the process [22].

\subsection{Pyrolysis reaction stages}

Saikia et al. [23] describe how the process occurs in two main stages. The primary stage which occurs at $600{ }^{\circ} \mathrm{C}$ and below includes the softening of coal, coke formation, release of vapors and development of plasticity. The aromatic carbon retained at this stage causes the coke formation while the hydro-aromatic carbon forms tar. Cracking that occurs

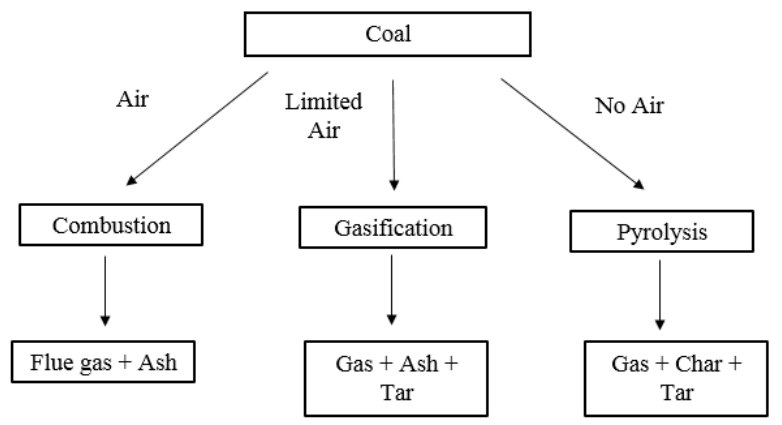

Fig. 4 Coal conversion pathways in the secondary stage results in gas formation, low mass molecules and poly-condensation products [23]. This is consistent with Serio et al.'s explanation [24] which is summarized on Fig. 5 which shows different stages of pyrolysis and the products that come with them. The first stage involves the breaking of bonds in the coal which leads to melting and formation of the metaplast. As the process continues, some molecules are released from further breaking of bonds leading to the development of tar, gases and char formation as in stage II of Fig. 5 [24]. Stage III comprises of product reactions where tar crack to form soot and other gases, the primary gases can crack to form lighter gases and soot while the char evolves into secondary gases such as $\mathrm{CO}$ and $\mathrm{H}_{2}$ [24].

Temperature is the most influential factor in pyrolysis. Thermal degradation reactions start occurring at temperatures of around $400{ }^{\circ} \mathrm{C}$ through the breakdown of weak bonds within the coal molecule possessing the lowest bonding energies [20]. Song et al. [25] described the five stages of pyrolysis according to the elevation in temperature as follows; drying stage, slow pyrolysis stage, fast pyrolysis stage, fast poly-condensation stage and slow poly-condensation stage. This information is important when considering coal utilization technology and products of interest.

The drying stage primarily involves the loss of inherent moisture. The second stage consists of the release of gases in the coal including carbon dioxide and methane. Stage three includes the initial pyrolysis reactions resulting in the release of Volatile Matter. The penultimate stage involves slow pyrolysis reaction and includes the cracking of larger tar molecules formed in the previous stage, while the final stage is characterized by the decomposition of char to form coke [25].

\subsection{Product evolution}

Knowledge on the evolution of species as the process progresses provides understanding of the mechanisms and its relation to coal structure. This can also be used as a guide for selecting suitable parameters leading to high yields of product of interest, e.g. tar. The pyrolysis process

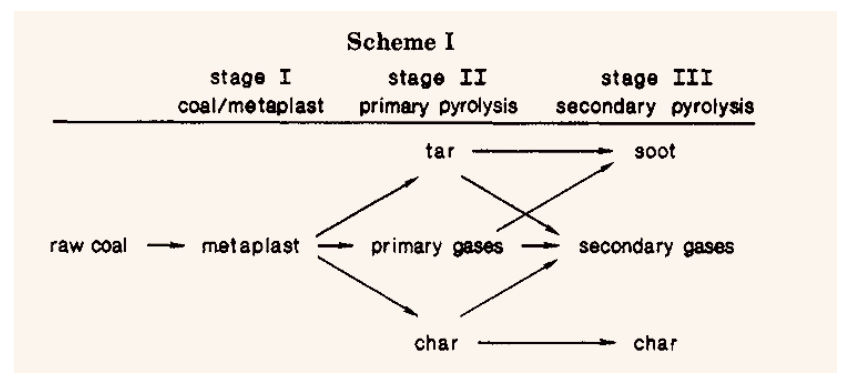

Fig. 5 Coal pyrolysis model 
parameters influence species evolution and product distributions by altering the reactions occurring in the different stages of pyrolysis [26].

The formation of tar results when larger ring fragments become hydrogen-saturated and distil as tar of medium molecular weight [27]. In a number of coals, this is primarily the first species released in pyrolysis reaction therefore it occurs at relatively low temperatures [24].

The tar however is prone to experience secondary vapor-phase reactions forming hydrocarbon carbons, soot and modified tar. As temperature rises, the composition of tar diminishes [28]. Ladner [20] found that at temperature above $1000{ }^{\circ} \mathrm{C}$ negligible tar is produced because the volatiles would have cracked into gaseous components. Furthermore, rapid heating supports high pyrolysis oil (often referred to as tar in literature) yield as opposed to slow heating. However, if the product of interest is a high viscosity tar, then slow heating rates can be beneficial due to cross linking [29]. High pressure opposes tar production but supports the methane and other hydrocarbon gas production. Table 2 shows the composition of pyrolysis products obtained with slow and rapid heating according to Ladner [20].

\subsubsection{Tar/oil production}

The formation of tar occurs in a series of stages which includes:

1. depolymerization by rupture of weaker bridges in the coal macromolecule to release smaller fragments,

2. re-polymerization of metaplastic molecules,

3. transport of lighter molecules away from the surface of the coal particles by combined vaporization and gas phase diffusion and

4. internal transport of lighter molecules to the surface of the coal particles and finally, the liquid phase in softening coal [30].

Tar formation occurs as molecular fragments broken down from the particle are released and transported out of the char particle without experiencing cross-linking reactions in the char particle. When cross-linking reactions occur, they cause the formation of a thicker tar product [29].

Table 2 Yields for slow and rapid heating

\begin{tabular}{lcc}
\hline & Slow & Rapid \\
\hline Gas & 8.4 & 7.3 \\
Water & 4.6 & 4.1 \\
Oil \& Tar & 14.8 & 26.4 \\
Char & 72.1 & 62.3 \\
\hline
\end{tabular}

Although mass transport does not seem to majorly influence the secondary reactions for the volatile species, it has been found to that it plays a significant role in the primary devolatization reactions which determine the yields of $\operatorname{tar}[30]$. The role of limitations of mass transfer seems to be experienced mostly in bituminous coal more than in other coal ranks [27]. Mass transport limitations involve a number of mechanisms, including but not limited to:

1. transport through coal pores,

2. transport of bubbles through the melt phase (softening coals only) and

3. transport of tars to the pores.

\subsubsection{Crosslinking reactions}

The break-up of the macro-molecular network in coal structure is controlled by rates of bond breaking, mass transport and crosslinking. Cross linking reactions determine the ultimate tar yield as well as the molecular distribution of the tar product [29]. This means that the greater the extent of these reactions, the higher the molecular weight of the tar, which would mean a more viscous product. Crosslinking can be associated with the decomposition of carboxyl groups in the coal molecule to form carbon dioxide [29]. In order to promote cross-linking, the heating rate should be slow as rapid heating has proven to substantially reduce the occurrence of these reactions [29]. Additionally, they can be promoted by oxidation [30].

A method of monitoring crosslinking reactions in coal works by measurement of solvent swelling ratio as described by Green in Deshpande et al. [29]. It is used to determine the crosslinking changes during pyrolysis. The extent of crosslinking reactions is dependent on the coal rank. Bituminous coal is said to crosslink at higher temperatures than lignite. Coal from Morupule Colliery is sub-bituminous to bituminous [1]; therefore, it is expected to crosslink at relatively high temperatures based on the latter statement.

\subsubsection{Char formation}

The solid residue obtained from exposing coal to high temperature through pyrolysis or gasification is char. It is comprised of molecular fragments which were unreleased or re-condensed during the process [27]. Elevated pyrolysis temperatures incite high carbon content and surface area of the char [24].

\subsubsection{Synthetic gas (syngas) production}

Syngas production is favored at higher temperature and the ultimate conditions for syngas production are in the gasification regime. By allowing the presence of limited 
air and/or steam, partial combustion takes place. The diagram in Fig. 6 [31] shows that lower ratios of oxygen vs. coal feed yield high synthesis gas $\left(\mathrm{H}_{2}\right.$ and $\left.\mathrm{CO}\right)$, until after ratio 1:1 where the yield starts decreasing as it approaches the complete combustion zone.

\section{Pyrolysis kinetics and mathematical modelling}

Although we are concerned about amounts of material that react, amounts of products that form, the quality and the rate at which they form (i.e. what happens at a macroscopic level) is driven by what happens on a molecular level. Collision of atoms with each other, energy levels to initiate reactions and even orientation of the molecules during collisions play a role and have to be considered (i.e. the chemical reaction mechanisms). Generally, the more collisions, the higher the probability of a reaction taking place. Various parameters affect the collision rate, of which the most common are temperature, pressure, concentration, surface areas and catalysts. Energy levels of the reactants need to be high enough to facilitate bond breaking.

Chemical reaction rates are influenced by thermodynamics and kinetics. While thermodynamic data tell us how much energy is gained or released if the reaction takes place, the kinetic factor is more important when considering reaction rates and many factors influence them, including:

1. the nature of the reactants

2. the phase of the reactants

3. temperature

4. pressure

5. concentration

6. surface area

7. catalysts.

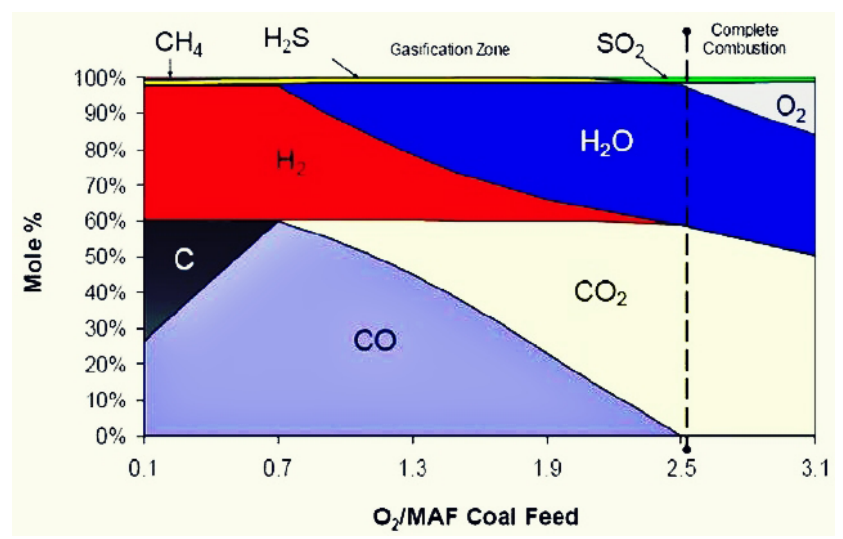

Fig. 6 Product of reactions for different $\mathrm{O}_{2}$ vs. Coal feed mole ratios during combustion
A number of mass transfer models have been proposed in coal pyrolysis [32]. A heat transfer model is required to predict the temperature history during non-isothermal/ isothermal pyrolysis process. The changes occurring to a particle under pyrolysis conditions in relation to heat transfer is dependent on particle size and reactor conditions, as is the case with mass transfer. It is fairly easier to predict temperature for particles under slow heating rates than for high heating rates (over $1000 \mathrm{~K} / \mathrm{s}$ ). It is important to have in consideration, the change in properties of the particle as it is heated up, in order to accurately determine the kinetic parameters of the process [32].

In Section 5 the most relevant kinetic, heat- and mass transfer models will be presented, which are used by many researchers, because these models can be applied very easy. The kinetic models, which will be presented in Section 5, are global kinetic models and they are not depending on the type of coal; thus, they can also be used to characterize the kinetic behavior of the sub-bituminous coal of Botswana.

\subsection{Single-step reaction kinetics}

Kinetics of the coal pyrolysis is very important, when we want to describe the weight loss in time. A simple kinetic model is the single-step reaction model, which is an empirical model and has the main assumption that coal pyrolysis has a single chemical reaction and it can be characterized by Arrhenius equation.

For solid-state chemical reactions:

coal $\stackrel{k}{\rightarrow} \alpha($ volatiles $)+(1-\alpha)($ char $)$

$\frac{d \alpha}{d t}=k(T) f(\alpha)$.

The $k(T)$ is the temperature dependent rate constant and can be substituted with the Arrhenius formula to obtain the non-isothermal kinetics as described by the Eq. (15):

$\frac{d \alpha}{d T}=\frac{A}{\beta} \exp \left(-\frac{E}{R T}\right) f(\alpha)$.

In paper [25] an experimental work is presented on coal pyrolysis kinetics. Four low rank coals were selected and their weight losses were measured in a thermogravimetric analyzer. The kinetic parameters (activation energy $(E)$ and frequency factor $(A)$ were defined by the single step first order reaction model using the Doyle integral method. The chemical structures of the coals were investigated by Fourier transform infrared spectroscopy 
measurements. The TGA measurements show that the five pyrolysis stages can be separated as:

- drying stage

- slow pyrolysis stage

- fast pyrolysis stage

- fast polycondensation stage

- slow polycondensation stage.

There is a comparison presented in the paper [33] between different coal pyrolysis kinetic models. The compared models are the following: single step first order reaction model, DAEM, and Functional Group Depolymerization, Vaporization and Crosslinking (FG-DVC) model. The conclusion was that the single step first order reaction model does not fit the experimental results with great accuracy. The use of the FG-DVC model is very quick and easy to use, represents the real process, and gives useful information about pyrolysis. To reproduce mass loss with a high accuracy, DAEM was the best option.

A mathematical model is described by [34] to analyze the pyrolysis of an isothermal coal particle. In this model five dimensionless groups are identified to help the calculations. Three dimensionless groups have influence on the pyrolysis kinetics. The heat of the pyrolysis is not ignored and it is demonstrated that the external heat transfer is controlling the kinetics of the process. This model uses the single step first order reaction model as a submodel to describe the kinetics.

Experimental work described in [35] investigated the effects of industrial microwave irradiation on the physicochemical properties and pyrolysis characteristics of a low rank coal. Using microwave irradiation, the drying process of the coal was 7.8 times faster than with hot air drying and the specific pore volume and total specific surface area were much higher. The tar production was increased from $1.3 \%$ to $8.5 \%$. The content of the polycyclic aromatic hydrocarbons was decreased from $26.4 \%$ to $22.7 \%$. For modeling the kinetics of the pyrolysis, the researchers used the single step first order reaction model.

Liu et al. [36] described a study, which investigates the Indonesian lignite, upgraded by ethanol and $n$-hexane. The reactivity and the chemical structure of the upgraded coal were analyzed in detail. The $\mathrm{H} / \mathrm{C}$ and $\mathrm{O} / \mathrm{C}$ ratios reduce with an increase of temperature. The quality of the coal was better with $n$-hexane upgrading than ethanol upgrading under the same conditions. Oxygen-containing functional groups were substituted with hydrogen and carbon-substituent groups during the upgrading process. The global kinetics of the pyrolysis process was modeled with a single step first order reaction model.

A comparison was made between coal-water slurry and its parent coal in Curie-point pyrolyser [37]. The kinetic parameters were calculated and the apparent activation energy obtained for the coal-water slurry was $16.362 \mathrm{~kJ} / \mathrm{mol}$ while for the parent coal it was $12.691 \mathrm{~kJ} / \mathrm{mol}$. The importance of the Curie-point pyrolyser is that it can keep the heating rate constant. The heating rates were $834 \mathrm{~K} / \mathrm{s}$ and $617 \mathrm{~K} / \mathrm{s}$.

A characterization of a bituminous coal is described by [38]. The kinetic parameters of coal pyrolysis were calculated with the Distributed Activation Energy Model. To describe the mechanism of the formation of the $\mathrm{H}_{2}$ and $\mathrm{C}_{2} \mathrm{H}_{2}$ gases they used the Málek method. The obtained reaction order was $n=2$. All standard models failed to fit the $\mathrm{CH}_{4}$ and $\mathrm{H}_{2} \mathrm{O}$ production, therefore the conclusion was that the formation of $\mathrm{CH}_{4}$ and $\mathrm{H}_{2} \mathrm{O}$ are more complex.

An experimental study presented by [39] used slag as the heat carrier. The single step first order reaction model was presented as the kinetic model, and CoatsRedfern and Málek method was selected to calculate the activation energies and frequency factors for two types of coal samples. They found that slag-to-coal ratio $(\mathrm{S} / \mathrm{C})$ has an effect on coal pyrolysis when the heating rate is $10 \mathrm{~K} / \mathrm{s}$ and $20 \mathrm{~K} / \mathrm{s}$, but there is no significant change when the heating rate is $40 \mathrm{~K} / \mathrm{s}$.

Jayaraman et al. [40] investigates the char structure, pyrolysis kinetics and evolved species of high ash coal at different heating rates using TGA and mass spectroscopy. SEM was used to explain the differences in structure based on char generation method. To define the global kinetic parameters, the single step first order reaction method was used.

\subsection{Multi-step kinetic model}

The multi-step kinetics model for coal pyrolysis assumes that there are several single-step reactions during coal pyrolysis. According to [41] the model is validated by comparing a very large set of experimental measurements relating to TGA measurements, pyroprobe, Curiepoint and drop-tube reactors. The predicted data from the model were in good agreement with the experimentally measured data. The activation energies and frequency factors were determined for thirty species. 


\subsection{Distributed Activation Energy Model}

The Distributed Activation Energy Model abbreviated as DAEM assumes that during coal pyrolysis a large number of parallel, irreversible and independent first-order reactions take place, with different activation energies but with the same frequency factor.

The equation is as follows:

$$
\alpha(T)=\int_{0}^{\infty}\left\{1-\exp \left[-\frac{A}{\beta} \int_{T_{0}}^{T} \exp \left(-\frac{E}{R T}\right) d T\right]\right\} f(E) d E
$$

where $f(E)$ is a Gaussian distribution described as:

$$
f(E)=\frac{1}{\sigma \sqrt{2 \pi}} \exp \left(-\frac{\left(E-E_{0}\right)^{2}}{2 \sigma^{2}}\right)
$$

$\sigma$ is the standard deviation and $E_{0}$ is the mean activation energy.

There is experimental work described by [42] on coal pyrolysis where the Coats-Redfern method was used to identify the pyrolysis reaction order. Activation energies were determined from the Starink model while DAEM was used for kinetic analysis. The Distributed Activation Energy Model was used to obtain the kinetic parameters of the coal pyrolysis in the paper based on experimental data [26].

A modified Arrhenius equation is proposed by [43] to predict the kinetic parameters of a pulverized-coal pyrolysis at different heating rates. It described the dependency of the activation energy and frequency factor on the heating rate. The extrapolation reliability of the proposed equation was validated by experimental data at different heating rates, and the results show that the equation can depict pyrolysis kinetics at different heating rates.

A continuously Distributed Activation Energy Model was used to describe the volatile yield from rapid pyrolysis of sub-bituminous coal [44]. There is an additional parameter introduced to the model, which can be determined from the basic characterization data of the coal, such as ash content.

\subsection{Heat and mass balance models based on DAEM and Multi-step kinetic models}

A mathematical model described on pyrolysis of a low rank coal using the DAEM kinetic model investigates the reaction behavior and heat transfer [45]. This DAEM model obtained a mean activation energy $(E)$ of $186.5 \mathrm{~kJ} / \mathrm{mol}$, frequency factor $(A)$ of $3.96 \times 10^{10} \mathrm{~s}^{-1}$ and a standard deviation of $39.5 \mathrm{~kJ} / \mathrm{mol}$. They predicted temperature profiles inside the coal particle. The proposed one-dimensional, time-dependent pyrolysis model can predict the chemical and physical phenomena that occurred during the process. The effect of the particle size was also investigated.
The assumptions of this model:

- The coal particle is a porous sphere.

- During pyrolysis the shape and size of the particle remains unchanged.

- The volatiles and the remained solid are in thermal equilibrium at any local position inside the coal particle.

- The pyrolysis products are only the solid char and the volatiles.

- Inside the coal particle the physical properties are homogeneous and isotropic.

- The mass transfer and convective heat transfer resistances of the volatile gases are ignored.

The heat balance equation:

$\frac{\partial\left(\rho c_{p} T\right)}{\partial t}=\frac{1}{r^{2}} \frac{\partial}{\partial r}\left(\lambda_{s} r^{2} \frac{\partial T}{\partial r}\right)+\rho_{0} R_{v} \Delta H$

where the main assumption is that heat change inside the particle is governed by heat of conduction and the endothermic reaction heat.

A mathematical model is presented in paper [46] to describe the heat transfer phenomena inside the coal particles. The model uses the DAEM kinetic model to investigate the volatile release during pyrolysis. The model was validated with published data from the literature.

A simulation of large coal particles pyrolysis is presented in a moving bed reactor by [47]. The heat carrier in this model is the circulating ash. The model is based on a multiple-independent parallel first-order reaction to describe the formation of the pyrolysis gases and tar $\left(\mathrm{CH}_{4}, \mathrm{CO}_{2}, \mathrm{H}_{2}, \mathrm{CO}, \mathrm{C}_{2} \mathrm{H}_{4}, \mathrm{C}_{2} \mathrm{H}_{6}, \mathrm{C}_{6} \mathrm{H}_{6}, \mathrm{C}_{7} \mathrm{H}_{8}, \mathrm{C}_{8} \mathrm{H}_{10}, \mathrm{C}_{10} \mathrm{H}_{8}\right.$, total Volatile Matter). The results show that the maximum heat difference was $406 \mathrm{~K}$ between the surface and core of $\operatorname{coal}\left(d_{p}=10 \mathrm{~mm}\right)$, at a bed height of $0.05 \mathrm{~m}$.

The evolution of the products $\left(\mathrm{CH}_{4}, \mathrm{CO}_{2}, \mathrm{H}_{2}, \mathrm{CO}, \mathrm{C}_{2} \mathrm{H}_{4}\right.$, $\mathrm{C}_{2} \mathrm{H}_{6}, \mathrm{C}_{6} \mathrm{H}_{6}, \mathrm{C}_{7} \mathrm{H}_{8}, \mathrm{C}_{8} \mathrm{H}_{10}, \mathrm{C}_{10} \mathrm{H}_{8}$, and the total Volatile Matter) is described with next formula:

$\frac{d w_{j}}{d t}=A_{j} \exp \left(-\frac{E_{j}}{R T}\right)\left(w_{j}^{*}-w_{j}\right)$

where $w_{j}$ is the mass fraction of gas, $j$ is the product that evolved up to time $t, w_{j}^{*}$ is the final mass fraction of the $j$ product gas obtained from a test of low temperature distillation of the coal, $A_{j}$ is the frequency factor for the selected product gas, $E_{j}$ is the activation energy for the gas $j$. For the calculation of the values for $E_{j}$ and $A_{j}$ the Coat-Redfern approximation was used. This model is able to predict changes in composition in different operating conditions. 


\subsection{The FD Model}

The Fragmentation and Diffusion model for coal pyrolysis helps in understanding the coal pyrolysis process by considering the fragments formed during thermal breakdown and how tar and other gases diffuse through these fragments. It also links this diffusion with pyrolysis primary gases release and secondary reactions. Mass transfer is an important and often neglected part of pyrolysis and this model considers it extensively. With this model, the behavior of high volatile release at high temperature as well as how coal with similar chemical compositions have different final yields is explained [48].

When heated, a coal molecule breaks into many fragments, with each fragment containing one or more structural units. If we consider a coal molecule with 2500 structural units then the sum of the weight in all units is the weight of the coal particle, using Gaussian distribution for molecular weight distribution. Since coal is made up of aromatic clusters and side chains, the mean molecular weight is estimated as:

$M_{a v}=M_{c l}+M_{\delta}$.

At any time, $t$, the number of fragments during pyrolysis is:

$\frac{d N_{f}}{d t}=k_{d}\left(N_{m}-N_{f}\right)$.

$N_{m}$ being the total number of structural units (2500),

$k_{d}=A_{d} e^{-\frac{E_{d}}{R T}}$

where $A_{d}=0.9 \mathrm{E} 7 \mathrm{~s}^{-1}$ and $E_{d}=$ activation energy $=47000 \mathrm{~J} / \mathrm{mol}$. The new fragments can be of tar or of gas as shown in Fig. 7.

In the Fragmentation and Diffusion pyrolysis model [48], a fragment is for gas if it contains only one structural unit, or it is for tar if its molecular weight is less that maximum tar molecular weight, $M_{\text {tar } \max }(800-1000$ amu for lignite and

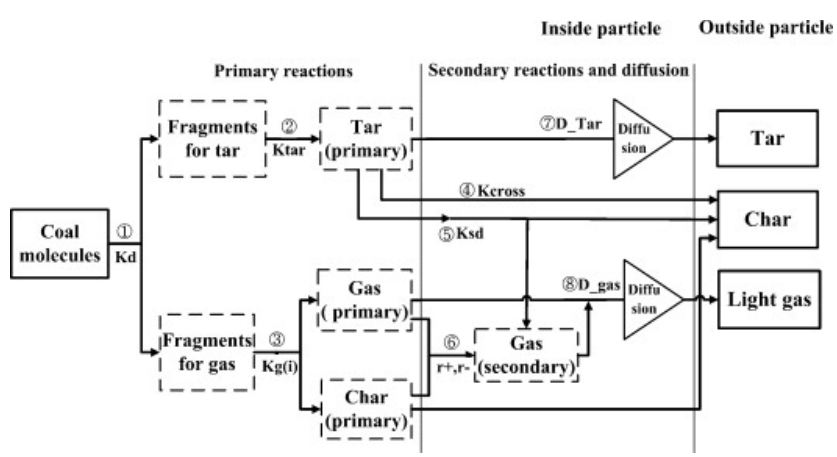

Fig. 7 Diagram of the Fragmentation and Diffusion pyrolysis model [48]. bituminous coals and 850 amu for bituminous coal). The $i^{\text {th }}$ fragment of $\operatorname{tar}\left(W_{\operatorname{tar}(i)}\right.$ weight percentage) will continuously crack into primary tar via reaction 2 in Fig. 7 such that [48]:

$\frac{d w_{\operatorname{tar}(i)}}{d t}=k_{\mathrm{tar}}\left(W_{\operatorname{tar}(i)}-w_{\operatorname{tar}(i)}\right) \quad\left(i=1 \sim N_{\text {ftar }}\right)$

where the reaction rate constant,

$k_{\mathrm{tar}}=A_{\mathrm{tar}} e^{-\frac{E_{\mathrm{tar}}}{R T}}$.

$A_{\mathrm{tar}}=0.43 \times 10^{7} \mathrm{~s}^{-1}, E_{\mathrm{tar}}=50149 \mathrm{~J} / \mathrm{mol}$ and $N_{\text {ftar }}$ is the total number of tar fragments.

Similarly, the weight percentage of the $h^{\text {th }}$ fragment of gases is $W_{\operatorname{gas}(h)}$, and $m_{(h, j, l)}$ is the weight percentage of the $j^{\text {th }}$ gas species produced from the corresponding $l^{\text {th }}$ functional group of the $h^{\text {th }}$ fragment of gases. Therefore, reaction 3 in Fig. 7 is such that:

$$
\begin{gathered}
\frac{d m_{(h, j, l)}}{d t}=k_{\text {gas }(l)}\left(n_{l} W_{\operatorname{gas}(h)}-m_{(h, j, l)}\right) ; \\
h=1 \sim N_{\text {fgas }}, \quad j=1 \sim 8
\end{gathered}
$$

$n_{l}$ is the $l^{\text {th }}$ functional group weight percentage. The reaction rate constant of the $l^{\text {th }}$ functional group is given by

$k_{\mathrm{gas}(l)}=A_{\operatorname{gas}(l)} e^{-E_{\mathrm{gas}(l)} R T}$

$N_{f \mathrm{gas}}$ is the total number of fragments for gases.

Following primary reactions, Volatile Matter goes through secondary reactions. Tar polymerizes to form char in the cross-linking reaction shown by Eq. (27):

$\frac{d w_{\text {tar_cro }}}{d t}=A_{c r o} e^{\left(-\frac{E_{c r o}}{R T}\right)} w_{\text {tar }}$.

Tar can also break down into small fragments to form gases and char in a cleavage reaction:

$\frac{d w_{\text {tar_sd }}}{d t}=A_{s d} e^{\left(-\frac{E_{s d}}{R T}\right)} w_{\text {tar }}$

where $W_{\text {tar }}$ is weight percentage of tar in pores, $W_{\text {tar_cro }}$ and $W_{\text {tar_sd }}$ are weight percentages undergoing crosslinking and secondary decomposition reactions. $A_{\text {cro }}=0.24 \times 10^{8} \mathrm{~s}^{-1}$, $E_{r c}=62040(\mathrm{~J} / \mathrm{mol}), A_{s d}=0.3 \times 10^{8} \mathrm{~s}^{-1}$ and $E_{s d}=105600 \mathrm{~J} / \mathrm{mol}$ with products of the cleavage reaction similar to those of reaction 3 in Fig. 7.

While the above reactions are happening, so is diffusion of gas and tar. Pore diffusion is expressed by the Knudsen diffusion equation:

$$
\frac{d q_{i}}{d t}=-D \frac{\partial c_{j}}{\partial y} A_{s}=D \frac{3 q_{i}}{r_{p}^{2}}
$$




$$
D\left(T, M_{i}\right)=9.7 \times 10^{3} r_{s} \sqrt{\frac{T}{M_{i}}}
$$

where, $q_{i}$ is the number of moles of species (gases or tar), $\partial C_{j} / \partial y$ is the concentration gradient, $A_{s}$ is the particle surface area, $r_{p}$ is particle radius, $M_{i}$ is molecular weight of species $i$ while $r_{s}$ is the average radius for micro pores. Equations (29) and (30) show that the larger the particle the longer the path for pore diffusion [48].

\section{Process control and optimization}

There has been almost no literature found on coal pyrolysis/gasification control. This is probably because process control is an important part of the Intellectual Property (IP) that gives companies or organizations a competitive edge over others in this area.

The most important parameters to control in the pyrolysis reactor are the feed rate, reactor temperature, heating rate of the material as it passes through the reactor and the residence time of the material in the heat zone of the reactor. The pyrolysis oil yield is also closely linked to the condensation rate and mist formation is one of the primary concerns during the condensation process. Once mist has formed it becomes a colloid in the vapor stream and is difficult to separate. An important part of pyrolysis process control is therefore to establish parameters which will prevent mist formation.

The pyrolysis pilot plant in BIUST (built by Pyro Carbon Energy (Pty) Ltd) is equipped with units to monitor pressure and temperature profile in the auger reactor, gas outlet, char outlet, the condenser and at the gasometer. Solids feed and discharge are controlled with pneumatic valves and feed rate and reactor residence times are controlled by variable speed drives. Heating is applied by means of induction heating which is controlled using an industrial PID controller. The unit also has provision to monitor material flow rates and all these will be used to design and optimize a process control scheme.

According to Uppal et al. [49], a control-oriented model of an underground coal gasification process is presented. The model is used in a robust control scheme of the heating value of the exit gas mixture, by manipulated the flow rate of the injected gases. Using the model, it is possible to infer some of the variables which are not possible to be measured. A nonlinear optimization procedure, Sequential Quadratic Programming (SQP) is used to calculate model parameters using process measurements.

Many optimization papers use optimization methods to adapt the models to the experimental or operational results. Some of the methods are used by the authors of this article to improve the quality of the models built for pyrolysis and gasification.

Tremel and Spliethoff [50] describe a model and optimization of coal gasification in entrained flow reactor. The predictions of the model were validated by experimental data. To achieve the maximum coal conversion and cold gas efficiency, optimization was used to define the best $\mathrm{O} / \mathrm{C}$ ratio. One cannot call this proper optimization since it was rather an experimental, non-organized search for the optimum. The $\mathrm{O} / \mathrm{C}$ was 0.95 which corresponds to a $65.8 \mathrm{t} / \mathrm{h}$ oxygen mass flow and $90.3 \mathrm{t} / \mathrm{h}$ fuel feed rate. With this operating condition the cold gas efficiency is $78 \%$ and the coal conversion is $99 \%$.

Vascellari et al. [51] describe a method to define the kinetic parameters of the coal pyrolysis for empirical kinetic models (single first order reaction model, competing two step model, DAEM) through a calibration from data predicted by phenomenological models or data from experiments using genetic algorithm as an optimization tool. The use of the genetic algorithm is necessary in this case to find the global minimum of the objective function which was set up. In this case, optimization methods are used to fit the model to experimental data only. No optimum was searched for.

Rakhshi and Wiltowski [52] present an optimization method, which is able to predict the final composition of the produced gas after pyrolysis of the coal. This model is based on the proximate and ultimate analysis of the coal. The model requires correction factors for $\mathrm{CO}_{2}$ and $\mathrm{C}_{2} \mathrm{H}_{6}$ and these factors are functions of the $\mathrm{CO}_{2}$ and $\mathrm{C}_{2} \mathrm{H}_{6}$ mass fractions and of the Volatile Matter content respectively, and can be optimized with minimization. The results of this model are in good agreement with the experimental data.

A two-dimensional axisymmetric mathematical model is presented in [53]. This model is able to predict the optimal oxygen injection rate for an underground coal gasification process. The authors defined that the maximum power $(2.3 \mathrm{MW})$ obtained from the process is due to a $14 \mathrm{~mol} / \mathrm{s}$ oxygen injection rate. If the injection rate of the oxygen exceeded $16 \mathrm{~mol} / \mathrm{s}$ the $\mathrm{CO}$ yield decreased and subsequently compromised power generation.

A review is presented on mathematical modeling for fluid-bed gasification in [54]. In this paper the modified eddy dissipation combustion model is described which assumes a two-step mechanism for $\mathrm{NO}_{\mathrm{x}}$ emissions, one equation for the reaction between $\mathrm{NH}_{3}$ and $\mathrm{O}_{2}$ and another one for $\mathrm{NH}_{3}$ and $\mathrm{NO}$ to form $\mathrm{N}_{2}$. The two objective functions are minimized using CFD to get the optimum $\mathrm{NO}_{\mathrm{x}}$ emission. 
From Kong et al. [55], a mathematical model is described on a gasification process in an entrained flow gasifier using the Aspen Plus simulator. The model is used to determine the optimal operation conditions considering the highest efficient syngas yield and lowest oxygen consumption. After model validation with industrial data, they found that the optimum $\mathrm{O}_{2} / \mathrm{C}$ ratio is in the range of $1.37-1.43 \mathrm{~kg} / \mathrm{kg}$. In this range the efficient syngas yield is higher and the oxygen consumption is lower.

He et al. [56] present a mathematical model for coal gasification in fixed-bed process. There is an optimization to find out the numbers of CSTRs (continuous stirredtank reactor) in different zones (combustion, gasification zones) of the fixed-bed reactor. They statement for modelling (using Aspen Plus simulator) is that in the combustion zone 7 RCSTRs is needed and for the gasification zone 13 RCSTRs respectively, to achieve a good coal conversion. Their simulation shows that the overall energy efficiency of the gasification system has a maximum value of about $72.4 \%$ at an $\mathrm{O}_{2} / \mathrm{C}$ ratio of 0.19 and a steam/C ration of 0.85 .

Another category of the optimization procedures refers to finding the optimal operational parameters. An experimental optimization approach using two-level factorial design of experiments, is described in [57] for bio gasification of a bituminous coal. The following optimum operating parameters were predicted:

- temperature $32^{\circ} \mathrm{C}$,

- particle size less than 73.99 micrometer,

- coal loading $201.98 \mathrm{~g} / \mathrm{L}$ and

- the ethanol concentration $300 \mathrm{mM}$.

For these predicted operating parameters, $74.2 \%$ methane content is associated. The methane content in the experiments was $70 \%$ which is in a good agreement with the results of the optimization based on the model. It is worthwhile to apply such experimental approach for many practical reasons, being:

- no model is needed in the first instance

- assures simple planning

- time saving

- less efforts

- faster experiments.

A review is presented in [58] on oxy-fuel combustion of pulverized coal. This summary includes a brief history of the oxy-fuel combustion technologies, thermodynamics, kinetics, heat and mass transfer, optimization of the flue gas recycle ratios and CFD modeling. The authors' recommendation is to increase the $\mathrm{O}_{2} / \mathrm{CO}_{2}$ ratio from $21 \% \mathrm{O}_{2} / 79 \% \mathrm{CO}_{2}$ to $30 \% \mathrm{O}_{2} / 70 \% \mathrm{CO}_{2}$ in oxy-coal combustions, because in this case the ash contains less residual coal, and the combustion reaches higher burnout efficiency than in air-fuel combustions.

Silva et al. [59] are using a CFD model of a pilot scale fluidized bed gasifier, to simulate the operating conditions to define the optimal operating regime. A $3^{k}$ factorial design to determine the optimal solid feeding rate, air flow rate and temperature was used. This, however, is not a proper optimization procedure which would include defining a scope function, constraints and using a numerical optimization method.

Hou and Zhang [60] use a proper optimization procedure for maximizing the Efficient Syngas fraction (ES, $\mathrm{H}_{2}+\mathrm{CO}$ ) in a Shell Coal Gasification Process (SCGP). Using the Taguchi method [61] and Response Surface Methodology, a Nelder-Mead algorithm was used to find out the optimal values for the main operational parameters to increase the fraction of ES at $98 \%$ :

- Oxygen/Coal ratio

- Pressure

- Steam/Coal ratio.

We have not identified any coal pyrolysis optimization approach in literature. However, it was observed that authors often incorrectly use the word "optimization", when they are searching empirically for the so-called optimal conditions. In spite of this quasi-empirical approach, we think that some of the methods and findings can be useful for studying gasification and pyrolysis using Botswana coal.

\section{Conclusion}

In developing thermochemical technology to convert Botswana coal into valuable products it is necessary to understand the characteristics of this coal and also the underlying reactions and kinetics of pyrolysis and gasification at a fundamental level. It is also necessary to understand the advantages and limitations of reactors and processes that have emerge historically in order to develop technology that is most suitable to typical Botswana coal.

Coal characterization is important in understanding coal potential in coal conversion technologies and optimizes its use. Proximate and ultimate analyses are ideal in understanding coal structure and formation, but to go further, more advanced microscopic instruments may be used. Coal gasification is necessary to further liberate fuel that is left in the char after the process of pyrolysis. Oxygen-coal feed ratio is optimal in producing syngas $\left(\mathrm{H}_{2}\right.$ and $\mathrm{CO}$ ) when it reaches a ratio of 1:1. 
The single-step kinetic models are very simple to use, but they have a disadvantage in that they are available for only one heating rate per coal sample. The DAEM is available for more heating rates but do not tell us anything about the species evolution - the only information we get is about the total volatiles evolution. The heat and mass transfer models are highly based on the pyrolysis kinetics and on the particle's characteristics, thus every time one has to carry out characterization of the coal to create an accurate model.

Pore diffusion coefficient has an important effect on volatile yields during pyrolysis as it influences diffusivity of these products. This effect is the reason why we can get different tar yields on coals with similar chemical compositions. Temperature, particle diameter and heating rate all have an effect on diffusivity as shown by the FD model. Results from the FD model can be relied upon as they also correspond to other numerical models.

Most of historic literature focuses on lignite and bituminous coal for pyrolysis due to their relatively high Volatile Matter content. However, since Botswana is not rich in these coals, the mathematical models will need to be adapted for sub-bituminous coals and these models will require extensive experimental validation.

\section{Acknowledgement}

The authors would like to appreciate the Botswana International University of Science and Technology and Pyro Carbon Energy for the financial support provided in this work.

\section{Nomenclature}

$A \quad$ frequency factor $\left[\mathrm{s}^{-1}\right]$

$A_{s} \quad$ particle surface area $\left[\mathrm{m}^{2}\right]$

a specific surface area $\left[\mathrm{m}^{-1}\right]$

$c_{p} \quad$ heat capacity $\left[\mathrm{J} \times \mathrm{kg}^{-1} \times \mathrm{K}^{-1}\right]$

$\stackrel{p}{D}$ diffusion coefficient $\left[\mathrm{m}^{2} \times \mathrm{s}^{-1}\right]$

$d \quad$ diameter of the coal particle [m]

E activation energy $\left[\mathrm{J} \times \mathrm{mol}^{-1}\right]$

$f \quad$ remaining solid fraction in the bed [-]

$\Delta H \quad$ reaction enthalpy $\left[\mathrm{J} \times \mathrm{kg}^{-1}\right]$

$h$ heat transfer coefficient $\left[\mathrm{J} \times \mathrm{m}^{-2} \times \mathrm{K}^{-1} \times \mathrm{s}^{-1}\right]$

$k \quad$ temperature dependent rate constant $\left[\mathrm{s}^{-1}\right]$

$k_{\text {gas }(l)} \quad$ reaction rate for the $l^{\text {th }}$ functional group $\left[\mathrm{s}^{-1}\right]$

$M^{\text {gas }(l)} \quad$ molecular weight $\left[\mathrm{kg} \times \mathrm{mol}^{-1}\right]$

$m_{(h, j, l)} \quad$ weight percentage of the $j^{\text {th }}$ gas species from the corresponding $l^{\text {th }}$ functional group for the $h^{\text {th }}$ fragment for gases [-]

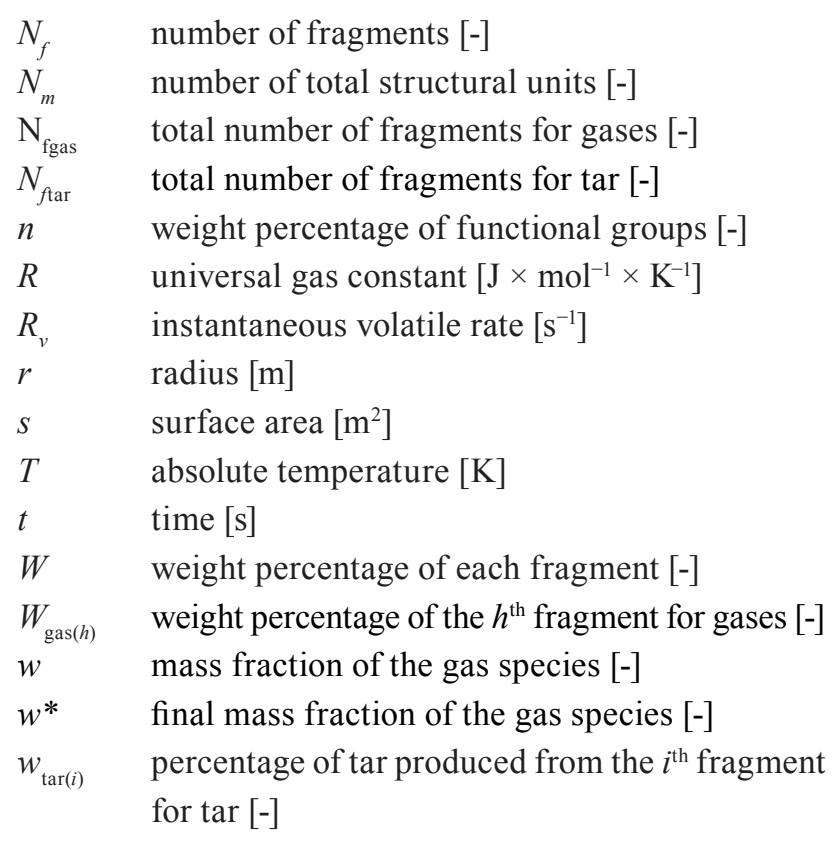

Greek letters

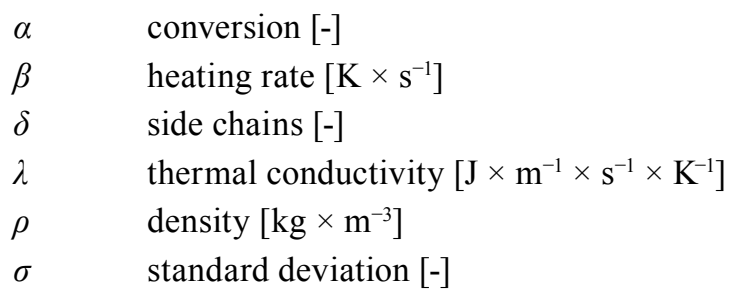

Indexes

$0 \quad$ initial state

av average

cl aromatic clusters

$i \quad$ the $i^{\text {th }}$ data point

$j \quad$ the $j^{\text {th }}$ gas species

tar tar inside the pores

tar_cro tar undergoing crosslink

tar_max maximum tar

tar_sd tar undergoing secondary decomposition reactions
Abbreviations
CFD Computational Fluid Dynamics
FD Fragmentation and Diffusion
TGA Thermogravimetric Analysis
DAEM Distributed Activation Energy Model
PID Proportional-Integral-Derivative 


\section{References}

[1] Grynberg, R. "Coal Exports and the Diversification of Botswana's Economy", Botswana Institute for Development Policy Analysis, 2012. [online] Available at: https://www.bidpa.bw/img_upload/ pubdoc_46.pdf [Accessed: 03 November 2018]

[2] Bordy, E. M., Catuneanu, O. "Sedimentology of the lower Karoo Supergroup fluvial strata in the Tuli Basin, South Africa", Journal of African Earth Sciences, 35(4), pp. 503-521, 2002.

https://doi.org/10.1016/S0899-5362(02)00129-X

[3] Schuler, E. "Low-carbon energy development scenarios for Africa Trade of fossil energy carriers", 2016. [online] Available at: https://esc.fnwi.uva.nl/thesis/centraal/files/f1145577.pdf [Accessed: 30 May 2018]

[4] Borah, R. C., Ghosh, P., Rao, P. G. "A review on devolatilization of coal in fluidized bed", International Journal of Energy Research 35(11), pp. 929-963, 2011.

https://doi.org/10.1002/er.1833

[5] Sharma, A., Pareek, V., Zhang, D. "Biomass pyrolysis-A review of modelling, process parameters and catalytic studies", Renewable and Sustainable Energy Reviews, 50, pp. 1081-1096, 2015.

https://doi.org/10.1016/j.rser.2015.04.193

[6] Hawkins, R., Nilsson, J., Oglesby, R., Day, D. "Utilization of Biomass Pyrolysis for Energy Production, Soil Fertility and Carbon Sequestration", [online] Available at: http://carbonchar. $\mathrm{com} / \mathrm{sites} /$ default/files/UN\%20SIDS\%20CSD-15\%20paper.pdf [Accessed: 27 March 2018]

[7] Bell, D. A., Towler, B. F., Fan, M. "Chapter 3 - Gasification Fundamentals", In: Coal Gasification and Its Applications, William Andrew Publishing, Kidlington, Oxford, UK, 2011, pp. 35-71. https://doi.org/10.1016/B978-0-8155-2049-8.10003-8

[8] Harris, D. J., Roberts, D. G., Henderson, D. G. "Gasification behaviour of Australian coals at high temperature and pressure", Fuel, 85(2), pp. 134-142, 2006.

https://doi.org/10.1016/j.fuel.2005.07.022

[9] Gupta, R. "Advanced Coal Characterization: A Review", Energy \& Fuels, 21(2), pp. 451-460, 2007. https://doi.org/10.1021/ef060411m

[10] Lu, Z., Mo, J., Yao, S., Zhao, J., Lu, J. "Rapid Determination of the Gross Calorific Value of Coal Using Laser-Induced Breakdown Spectroscopy Coupled with Artificial Neural Networks and Genetic Algorithm", Energy \& Fuels, 31(4), pp. 3849-3855, 2017. https://doi.org/10.1021/acs.energyfuels.7b00025

[11] Cairncross, B. "An overview of the Permian (Karoo) coal deposits of southern Africa", Journal of African Earth Sciences, 33(3-4), pp. 529-562, 2001.

https://doi.org/10.1016/S0899-5362(01)00088-4

[12] Miller, B. G., Tillman, D. A. "Chapter 2 - Coal Characteristics", In: Combustion Engineering Issues for Solid Fuel Systems, Academic Press, Burlington, MA, USA, 2008, pp. 33-81. https://doi.org/10.1016/B978-0-12-373611-6.00002-1

[13] Speight, J. G. "Handbook of Coal Analysis", vol. 166, John Wiley \& Sons, Hoboken, New Jersey, USA, 2005. https://doi.org/10.1002/0471718513

[14] Kiran, S. P. "Properties of Coal", pp. 2-7, 2011. [online] Available at: https://www.scribd.com/document/48566717/4-1-3-Propertiesof-Coals [Accessed: 20 January 2017]
[15] O'Brien, G., Jenkins, B., Esterle, J., Beath, H. "Coal characterisation by automated coal petrography", Fuel, 82(9), pp. 1067-1073, 2003. https://doi.org/10.1016/S0016-2361(02)00428-3

[16] Liu, B., He, Q., Jiang, Z., Xu, R., Hu, B. "Relationship between coal ash composition and ash fusion temperatures", Fuel, 105, pp. 293-300, 2013. https://doi.org/10.1016/j.fuel.2012.06.046

[17] Jak, E. "Prediction of coal ash fusion temperatures with the $\mathrm{F}^{*} \mathrm{~A}^{*} \mathrm{C}^{*} \mathrm{~T}$ thermodynamic computer package", Fuel, 81(13), pp. $1655-1668,2002$. https://doi.org/10.1016/S0016-2361(02)00091-1

[18] Balachandran, M. "Role of Infrared Spectroscopy in Coal Analysis-An Investigation", American Journal of Analytical Chemistry, 5(6), pp. 367-372, 2014. https://doi.org/10.4236/ajac.2014.56044

[19] Potgieter-Vermaak, S., Maledi, N., Wagner, N., Van Heerden, J. H. P., Van Grieken, R., Potgieter, J. H. "Raman spectroscopy for the analysis of coal: a review", Journal of Raman Spectroscopy, 42(2), pp. 123-129, 2011.

https://doi.org/10.1002/jrs.2636

[20] Ladner, W. R. "The products of coal pyrolysis: properties, conversion and reactivity", Fuel Processing Technology, 20, pp. 207-222, 1988. https://oi.org/10.1016/0378-3820(88)90021-5

[21] Xu, W.-C., Tomita, A. "The effects of temperature and residence time on the secondary reactions of volatiles from coal pyrolysis", Fuel Processing Technology, 21(1), pp. 25-37, 1989. https://doi.org/10.1016/0378-3820(89)90012-X

[22] Jüntgen, H. "Review of the kinetics of pyrolysis and hydropyrolysis in relation to the chemical constitution of coal", Fuel, 63(6), pp. 731-737, 1984. https://oi.org/10.1016/0016-2361(84)90058-9

[23] Saikia, B. K., Saikia, A., Baruah, B. P. "Nature and Chemistry of Coal and Its Products", In: Riazi, M. R., Gupta, R. (eds.) Coal Production and Processing Technology, CRC Press, Boca Raton, USA, 2015, pp. 3-30.

[24] Serio, M. A., Hamblen, D. G., Markham, J. R., Solomon, P. R. "Kinetics of Volatile Product Evolution in Coal Pyrolysis: Experiment and Theory", Energy \& Fuels, 1(2), pp. 138-152, 1987. https://doi.org/10.1021/ef00002a002

[25] Song, H., Liu, G., Zhang, J., Wu, J. "Pyrolysis characteristics and kinetics of low rank coals by TG-FTIR method", Fuel Processing Technology, 156, pp. 454-460, 2017. https://doi.org/10.1016/j.fuproc.2016.10.008

[26] Tian, B., Qiao, Y., Bai, L., Feng, W., Jiang, Y., Tian, Y. "Pyrolysis behavior and kinetics of the trapped small molecular phase in a lignite", Energy Conversion and Management, 140, pp. 109-120, 2017. https://doi.org/10.1016/j.enconman.2017.02.077

[27] Solomon, P. R., Fletcher, T. H., Pugmire, R. J. "Progress in coal pyrolysis", Fuel, 72(5), pp. 587-597, 1993. https://doi.org/10.1016/0016-2361(93)90570-R

[28] Luo, K., Zhang, C., Zhu, S., Bai, Y., Li, F. "Tar formation during coal pyrolysis under $\mathrm{N}_{2}$ and $\mathrm{CO}_{2}$ atmospheres at elevated pressures", Journal of Analytical and Applied Pyrolysis, 118, pp. 130-135, 2016. https://doi.org/10.1016/j.jaap.2016.01.009 
[29] Deshpande, G. V., Solomon, P. R., Serio, M. A. "Crosslinking reactions in coal pyrolysis", In: American Chemical Society Division of Fuel Chemistry meeting, Toronto, Canada, 1988, OSTI ID: 6594411. [online] Available at: https://www.osti.gov/biblio/6594411 [Accessed: 20 January 2017]

[30] Solomon, P. R., Hamblen, D. G., Carangelo, R. M., Serio, M. A., Deshpande, G. V. "General model of coal devolatilization", Energy \& Fuels, 2(4), pp. 405-422, 1988. https://doi.org/10.1021/ef00010a006

[31] Wang, P., Massoudi, M. "Effect of Coal Properties and Operation Conditions on Flow Behavior of Coal Slag in Entrained Flow Gasifiers: A Brief Review", U.S. Department of Energy, National Energy Technology Laboratory, Pittsburgh, PA, USA, Rep. DOE/ NETL-2011/1508, 2011. [online] Available at: https://digital.library. unt.edu/ark:/67531/metadc834806/ [Accessed: 23 May 2018]

[32] Solomon, P. R., Serio, M. A., Suuberg, E. M. "Coal pyrolysis: Experiments, kinetic rates and mechanisms", Progress in Energy and Combustion Science, 18(2), pp. 133-220, 1992. https://doi.org/10.1016/0360-1285(92)90021-R

[33] Arenillas, A., Rubiera, F., Pevida, C., Pis, J. J. "A comparison of different methods for predicting coal devolatilisation kinetics", Journal of Analytical and Applied Pyrolysis, 58-59, pp. $685-701,2001$. https://doi.org/10.1016/S0165-2370(00)00183-2

[34] Chern, J.-S., Hayhurst, A. N. "A simple theoretical analysis of the pyrolysis of an isothermal particle of coal", Combustion and Flame, 157(5), pp. 925-933, 2010. https://doi.org/10.1016/j.combustflame.2009.12.003

[35] Zhou, G., Huang, Q., Yu, B., Tong, H., Chi, Y., Yan, J. "Effect of industrial microwave irradiation on the physicochemical properties and pyrolysis characteristics of lignite", Chinese Journal of Chemical Engineering, 26(5), pp. 1171-1178, 2018. https://doi.org/10.1016/j.cjche.2017.11.002

[36] Liu, M., Li, J., Duan, Y. "Effects of solvent thermal treatment on the functional groups transformation and pyrolysis kinetics of Indonesian lignite", Energy Conversion and Management, 103, pp. 66-72, 2015.

https://doi.org/10.1016/j.enconman.2015.06.047

[37] Wang, H., Jiang, X., Liu, H., Wu, S. "Fast pyrolysis comparison of coal-water slurry with its parent coal in Curie-point pyrolyser", Energy Conversion and Management, 50(8), pp. 1976-1980, 2009. https://doi.org/10.1016/j.enconman.2009.04.012

[38] Zou, C., Ma, C., Zhao, J., Shi, R., Li, X. "Characterization and non-isothermal kinetics of Shenти bituminous coal devolatilization by TG-MS", Journal of Analytical and Applied Pyrolysis, 127, pp. 309-320, 2017.

https://doi.org/10.1016/j.jaap.2017.07.020

[39] Duan, W., Yu, Q., Xie, H., Qin, Q. "Pyrolysis of coal by solid heat carrier-experimental study and kinetic modeling", Energy, 135, pp. 317-326, 2017.

https://doi.org/10.1016/j.energy.2017.06.132

[40] Jayaraman, K., Gokalp, I., Bostyn, S. "High ash coal pyrolysis at different heating rates to analyze its char structure, kinetics and evolved species", Journal of Analytical and Applied Pyrolysis, 113, pp. 426-433, 2015.

https://doi.org/10.1016/j.jaap.2015.03.007
[41] Sommariva, S., Maffei, T., Migliavacca, G., Faravelli, T., Ranzi, E. "A predictive multi-step kinetic model of coal devolatilization", Fuel, 89(2), pp. 318-328, 2010. https://doi.org/10.1016/j.fuel.2009.07.023

[42] Liu, J., Ma, J., Luo, L., Zhang, H., Jiang, X. "Pyrolysis of superfine pulverized coal. Part 5. Thermogravimetric analysis", Energy Conversion and Management, 154, pp. 491-502, 2017. https://doi.org/10.1016/j.enconman.2017.11.041

[43] Du, R.-L., Wu, K., Xu, D.-A., Chao, C.-Y., Zhang, L., Du, X.-D. "A modified Arrhenius equation to predict the reaction rate constant of Anyuan pulverized-coal pyrolysis at different heating rates", Fuel Processing Technology, 148, pp. 295-301, 2016. https://doi.org/10.1016/j.fuproc.2016.03.011

[44] Ulloa, C., Gordon, A. L., García, X. "Distribution of activation energy model applied to the rapid pyrolysis of coal blends", Journal of Analytical and Applied Pyrolysis, 71(2), pp. 465-483, 2004. https://doi.org/10.1016/S0165-2370(03)00132-3

[45] Wang, J., Lian, W., Li, P., Zhang, Z., Yang, J., Hao, X., Huang, W., Guan, G. "Simulation of pyrolysis in low rank coal particle by using DAEM kinetics model: Reaction behavior and heat transfer", Fuel, 207, pp. 126-135, 2017. https://doi.org/10.1016/j.fuel.2017.06.078

[46] Liu, X., Wang, G., Pan, G., Wen, Z. "Numerical analysis of heat transfer and volatile evolution of coal particle", Fuel, 106, pp. 667-673, 2013. https://doi.org/10.1016/j.fuel.2012.10.072

[47] Zhang, Y.-Q., Zhu, J.-L., Wang, X.-H., Zhang, X.-W., Zhou, S.-X., Liang, P. "Simulation of large coal particles pyrolysis by circulating ash heat carrier toward the axial dimension of the moving bed", Fuel Processing Technology, 154, pp. 227-234, 2016. https://doi.org/10.1016/j.fuproc.2016.08.037

[48] Chen, Y., He, R. "Fragmentation and diffusion model for coal pyrolysis", Journal of Analytical and Applied Pyrolysis, 90(1), pp. 72-79, 2011. https://doi.org/10.1016/j.jaap.2010.10.007

[49] Uppal, A. A., Bhatti, A. I., Aamir, E., Samar, R., Khan, S. A. "Control oriented modeling and optimization of one dimensional packed bed model of underground coal gasification", Journal of Process Control, 24(1), pp. 269-277, 2014. https://doi.org/10.1016/j.jprocont.2013.12.001

[50] Tremel, A., Spliethoff, H. "Gasification kinetics during entrained flow gasification - Part III: Modelling and optimisation of entrained flow gasifiers", Fuel, 107, pp. 170-182, 2013. https://doi.org/10.1016/j.fuel.2013.01.062

[51] Vascellari, M., Arora, R., Hasse, C. "Simulation of entrained flow gasification with advanced coal conversion submodels. Part 2: Char conversion", Fuel, 118, pp. 369-384, 2014. https://doi.org/10.1016/j.fuel.2013.11.004

[52] Rakhshi, A., Wiltowski, T. "A framework for devolatilization breakdown in entrained flow gasification modeling", Fuel, 187, pp. 173-179, 2017. https://doi.org/10.1016/j.fuel.2016.09.036

[53] Perkins, G., Sahajwalla, V. "Modelling of Heat and Mass Transport Phenomena and Chemical Reaction in Underground Coal Gasification", Chemical Engineering Ressearch and Design, 85(3), pp. 329-343, 2007. https://doi.org/10.1205/cherd06022 
[54] Singh, R. I., Brink, A., Hupa, M. "CFD modeling to study fluidized bed combustion and gasification", Applied Thermal Engineering, 52(2), pp. 585-614, 2013.

https://doi.org/10.1016/j.applthermaleng.2012.12.017

[55] Kong, X., Zhong, W., Du, W., Qian, F. "Compartment modeling of coal gasification in an entrained flow gasifier: A study on the influence of operating conditions", Energy Conversion and Management, 82, pp. 202-211, 2014.

https://doi.org/10.1016/j.enconman.2014.01.055

[56] He, C., Feng, X., Chu, K. H. "Process modeling and thermodynamic analysis of Lurgi fixed-bed coal gasifier in an SNG plant", Applied Energy, 111, pp. 742-757, 2013. https://doi.org/10.1016/j.apenergy.2013.05.045

[57] Zhang, J., Liang, Y., Harpalani, S. "Optimization of methane production from bituminous coal through biogasification", Applied Energy, 183, pp. 31-42, 2016.

https://doi.org/10.1016/j.apenergy.2016.08.153

[58] Chen, L., Yong, S. Z., Ghoniem, A. F. "Oxy-fuel combustion of pulverized coal: Characterization, fundamentals, stabilization and CFD modeling", Progress in Energy and Combustion Science, 38(2), pp. 156-214, 2012.

https://doi.org/10.1016/j.pecs.2011.09.003
[59] Silva, V., Couto, N., Eusébio, D., Rouboa, A., Brito, P., Cardoso, J., Trninic, M. "Multi-stage optimization in a pilot scale gasification plant", International Journal of Hydrogen Energy, 42(37), pp. 23878-23890, 2017.

https://doi.org/10.1016/J.IJHYDENE.2017.04.261

[60] Hou, J., Zhang, J. "Robust optimization of the efficient syngas fractions in entrained flow coal gasification using Taguchi method and response surface methodology", International Journal of Hydrogen Energy, 42(8), pp. 4908-4921, 2017. https://doi.org/10.1016/j.ijhydene.2017.01.027

[61] Karna, S. K., Sahai, R. "An Overview on Taguchi Method", International Journal of Engineering and Mathematical Sciences, 1(1), pp. 1-7, 2012. [online] Available at: http://ijems.org/ uploads/10808563670IJEMS1.pdf [Accessed: 15 April 2018] 